\title{
O SIGNIFICADO DA CIRURGIA CARDÍACA E DO TOQUE NA PERSPECTIVA DE PACIENTES INTERNADOS EM UTI*
}

\author{
THE MEANING OF CARDIAC SURGERY AND THE TOUCH IN THE (A) PERSPECTIVE OF INTERNEES \\ PATIENTS IN INTENSIVE CARE

\section{EL SIGNINIFICADO DE LA CIRURGIA CARDIACA Y DE LO TOQUE EN LA PERSPECTIVA DE PACIENTES INTERNADOS EN UTI}

\section{Edna de Souza Batista Brandãoํㅜㄹ Maria Regina de Carvalho Melo Bastos ${ }^{1}$, Vanessa da Silva Carvalho Vila ${ }^{2}$}

RESUMO: Este estudo buscou compreender o significado da cirurgia e do toque na perspectiva de 11 pacientes nos pós-operatório, internados na UTI do Hospital das Clínicas da Universidade Federal de Goiás, no período de julho a agosto de 2001. Trata-se de uma pesquisa descritiva, fundamentada nos pressupostos da abordagem qualitativa, realizada por meio de observações participantes e entrevistas semiestruturadas. Dos dados, emergiram duas categorias principais que deram sentido aos significados da cirurgia cardíaca e do toque na UTI: "cirurgia cardíaca" e "o toque". Da análise foi possível observar que toque tem um significado que envolve essencialmente o aspecto afetivo, como a segurança, a confiança, o conforto, a tranqüilidade, a compreensão, o olhar com interesse, o encorajamento, enfim, uma forma terapêutica que capacita o profissional para cuidar de pacientes e familiares de forma consciente e humana.

PALAVRAS CHAVE: Cuidados Intensivos; Comunicação Não Verbal; Cirurgia Torácica.

ABSTRACT: This study searched for an understanding of the cardiac surgery and the touch meaning in the perspective of 11 patients in post operative time that had been in at the Federal University of Goiás Clinical Intensive Unit, from July to August, 2001. It was a descriptive research based in a qualitative design. To collect the data was done by observation and semistructured interviews. After analyzing the data, two main categories took place giving especial sense to the meaning of cardiac surgery and to the touch in intensive care: "cardiac surgery" and "the touch". From the analysis it was possible to observe that the touch has a meaning that involves essentially the affective aspect, as safety, reliance, comfort, tranquility, comprehension, looking with interest, the encouragement, and at last, an another therapeutic way that makes the professional able to take care of familiars and patients in a consciously and human way.

KEY WORDS: Intensive Care; Nonverbal Communication; Thoracic Surgery.

RESUMEN: Con este estudio se buscó comprender el significado de la cirugía y del toque en la perspectiva de 11 pacientes en los pos-operatorio, internados en la UTI del Hospital de las Clínicas de al Universidad
Federal de Goiás, en el periodo de julio hasta agosto de 2001. Se trata de una pesquisa descriptiva basada en los presupuestos del abordaje cualitativo. Para la colecta de datos fueron realizadas observaciones participantes y entrevistas semi-estructuradas. Con el análisis de los datos, emergieron dos categorías principales que dieron sentido al los significados de la cirugía cardiaca y del toque en la UTI: "cirugía cardiaca" y "el toque". De la analice de los datos fuera posible observar que el toque tiene un significado que envuelve esencialmente el aspecto afectivo, como la seguridad, la confianza, el conforto, la tranquilidad, la compresión, la mirada con interese, el alentamiento, en fin, una forma terapéutica que capacita el profesional a cuidar de pacientes y familiares de forma consciente y humana.

PALABRAS CLAVE: Cuidados Intensivos; Comunicación No Verbal; Cirugía Torácica.

\footnotetext{
${ }^{1}$ Enfermeira. Especialista Enfermagem em UTI pela Universidade Federal de Goiás. Goiânia, GO.

2 Enfermeira Mestre em Enfermagem pelo Departamento de Enfermagem Geral e Especializada da Escola de Enfermagem de Ribeirão preto da Universal de São Paulo. Professor Assistente I do Departamento de Enfermagem e Fisioterapia da Universidade Católica de Goiás. Goiânia, GO . Contatos: scvila@uol.com.br.
} 


\section{INTRODUÇÃO}

Em função de nossa vivência como enfermeiras da Unidade de Terapia Intensiva (UTI) do Hospital das Clínicas da Universidade Federal de Goiás (HC/UFGO), prestando cuidados a pacientes críticos, constatamos o quanto a internação nesta unidade gera sentimentos de ansiedade, insegurança e acima de tudo medo da doença, da dor e da morte. Estar separado da família reforça a sensação de desalento e desamparo. Observamos que os pacientes cardíacos internados na UTI, principalmente aqueles que se submeteram à cirurgia cardíaca, sentem-se angustiados e amedrontados perante a gravidade do diagnóstico e pelo temor da morte.

BARCELLOS \& CAMPONAGRA (2001) enfatizam que, principalmente no pós-operatório, o paciente cardíaco pode ser ajudado a adquirir uma melhor qualidade de vida, desde que seja assistido por profissionais que ajudem no restabelecimento, minimizando complicações físicas e emocionais decorrentes do processo de adoecimento.

O pós-operatório imediato da cirurgia cardíaca acontece nas Unidades de Terapia Intensiva e neste período, o enfoque maior do cuidado está relacionado à recuperação da anestesia e à estabilidade hemodinâmica. No entanto, os profissionais jamais deveriam esquecer que nesta fase o paciente se encontra fragilizado em decorrência do estresse físico e emocional, que poderá ser agravado com as atividades desenvolvidas neste ambiente.

BARCELLOS \& CAMPONAGRA (2001) afirmam que apesar dos avanços técnicos, as fantasias a respeito do coração, órgão único e centralizador, não foram amenizadas. BARBATO et al (1982) constataram que os pacientes adultos submetidos à cirurgia cardíaca relatam como principal problema o ambiente desconhecido e agressivo e relacionam diversos problemas psicossociais e espirituais manifestados pelos pacientes cardíacos internados em UTI, entre eles a falta da família, o medo de morrer, o medo de exames e da cirurgia, a preocupação com o trabalho, as rotinas a que são submetidos como o fato de ficar sem roupas, entre outros.

A separação dos familiares, a baixa auto-estima e auto-imagem são fatores que dificultam o enfrentamento deste momento de dor e sofrimento. Nesta perspectiva, é necessário que a equipe multiprofissional, em especial, a enfermagem, esteja atenta aos processos psicológicos por que passa o paciente cardíaco internado em UTI e dos familiares. Os pacientes devem ser estimulados a participar do processo de recuperação da saúde, através da comunicação e dos sentimentos de apoio e confiança a ele transmitidos para reduzir sua ansiedade e aumentar sua dignidade (HUDAK \& GALLO, 1997, BARCELLOS \& CAMPONOGARA, 2001).

SILVA (1996) esclarece que cuidar de um paciente não significa apenas tratar o seu físico, mas principalmente sua identidade, suas dimensões psicossociais e psicobiológicas.

Considerando os aspectos físicos e emocionais dos pacientes submetidos a cirurgia cardíacas durante a internação na UTI, sentimos a necessidade de compreender o significado dessa situação e do toque na perspectiva desses. Acreditamos que o toque pode ser considerado como um cuidado complementar às terapias tecnológicas modernas, utilizado para reduzir a ansiedade, o estresse e a dor.

Nossa percepção sobre a importância do toque é reforçada pelas afirmações de SILVA (1996) acerca da necessidade do paciente quando se sente sozinho, está com dor, triste, deprimido, com a consciência diminuída e também nas situações vivenciadas pelos pacientes no pós-operatório de cirurgia cardíaca.

Nesta perspectiva, nas unidades de terapia intensiva, onde a despersonalização do paciente é habitual, em vista da utilização de equipamentos e máquinas, a necessidade do toque é acentuada, principalmente, quando não se destina apenas à execução das tarefas de enfermagem, mas, quando traduz atenção, afeto e companhia.

HUDAK \& GALLO (1997) afirmam que a permanência em UTI é uma experiência assustadora e desumanizada, porque impede o paciente de perceber os limites de seu próprio corpo devido ao uso de equipamentos. Na UTI, quando se está com medo, ansioso ou deprimido, receber um toque carinhoso pode ser divino. O paciente tem privação sensorial, barreiras corpóreas para tocar o próprio corpo, para comunicar-se com os outros e perde o contado diário com a família. Tudo isso altera sua capacidade de recuperação (SILVA, 2000).

Segundo HUDAK \& GALLO (1997), mesmo no caso de estarem privados de sensibilidade ao toque, os paciente de UTI podem ser por ele beneficiados, desde que seja planejado pelo profissional. O toque pode ser utilizado para transmitir mensagens ao paciente sobre si próprio, para a percepção do seu corpo e sua auto-estima.

O toque é uma linguagem e, desde o nascimento todas as pessoas têm necessidade de contato tátil, essencial para o seu desenvolvimento, acentuada durante os períodos em que há exposição ao estresse. Nos processos que envolvem enfermidades, o toque é um dos instrumentos de recuperação utilizados pela enfermagem para transmitir sentimento de bem-estar ao paciente (FIGUEIREDO et al, 1996).

Tocar é tudo o que acontece entre um corpo e outro: afagar, segurar, acariciar, alisar. Olhar com interesse é uma forma de toque. No contexto da enfermagem, o toque pode ser visto de várias perspectivas, mas principalmente como uma estratégia de cuidar que envolve a efetiva interação entre paciente, família e equipe multiprofissional (FIGUEIREDO et al, 1996). 
Segundo FIGUEIREDO et al (1996) para tocar o corpo do outro de maneira efetiva, é imprescindível conhecê-lo e pensar na dimensão humana e espiritual dos sentidos. Assim, será possível entender que a prática do cuidar/cuidado envolve não só o tocar com as mãos, mas com o cheiro, a voz, o olhar e os gestos corporais.

O toque exerce efeitos benéficos nas situações de medo e estresse, ou quando o paciente se encontra em situação de perda da identidade, de desorientação no tempo e espaço, ou ainda, em pacientes que necessitem de encorajamento (HUDAK \& GALLO, 1997). Por meio do toque, os enfermeiros podem transmitir inúmeras mensagens: segurança, compreensão, sinceridade, respeito, apoio, cordialidade, preocupação, tranqüilização, empatia, conforto, proximidade, encorajamento, aceitação, desejo de ajudar, entre outros (HUDAK \& GALLO, 1997).

FIGUEIREDO et al (1996) afirmam que o toque "consiste da matriz de todos os sentidos, o qual oferece determinado significado humano à pele, tratando-se de uma ação reveladora da dimensão da capacidade humana. Da mesma forma os estímulos que ali são provocados trocam energias entre 0 cuidador e a pessoa que recebe esse cuidado pela enfermagem e, complementando, MONTAGU apud FIGUEIREDO et al (1996) afirma que por meio do toque começam o amor e a amizade. Como profissionais consideramos que o aprofundamento neste tema poderá melhorar nossa atuação e estimular estudos posteriores acerca do significado da cirurgia cardíaca e do toque na perspectiva de pacientes no pós-operatório de cirurgia cardíaca internados em UTI.

\section{OBJETIVO}

Este estudo tem como objetivo compreender o significado da cirurgia cardíaca e do toque na perspectiva de pacientes em pós-operatório de cirurgia cardíaca, internados na UTI do Hospital das Clínicas da Universidade Federal de Goiás.

\section{METODOLOGIA}

A pesquisa na área de saúde requer a análise dos aspectos estruturais do problema estudado, numa base empírica, aliada a uma visão subjetiva que permita a compreensão da realidade humana, por meio da explicação dos fenômenos que constituem a vivência das relações sociais. A presente pesquisa foi descritiva, segundo os pressupostos da metodologia qualitativa. Desenvolvida considerando os seguintes passos: a escolha da situação social, o trabalho de campo e a análise e interpretação dos dados.
A situação social selecionada focalizou a percepção de pacientes, admitidos na UTI do HC/UFGO, sobre o toque no pós-operatório de cirurgias cardíacas, entidade pública e de grande porte. Dos 343 leitos, 19 são da UTI.

Os informantes deste estudo foram pacientes adultos, conscientes, de ambos os sexos, no pós-operatório de cirurgia cardíaca que concordaram em participar, e assinaram o termo de consentimento informado, após conhecerem os objetivos da pesquisa. A coleta de dados ocorreu de julho a agosto de 2001.

\section{O trabalho de campo}

O trabalho de campo constitui uma etapa essencial da metodologia qualitativa, envolvendo a coleta de dados, a delimitação do foco de estudo e o registro de dados. Para MINAYO (1998), representa o recorte espacial que corresponde à abrangência, do recorte teórico correspondente ao objeto da investigação.

Foram observados os cuidados prestados ao paciente no pós-operatório de cirurgia cardíaca. Foi solicitado aos participantes o consentimento formal e verbal para sua realização. Simultaneamente foram realizadas as entrevistas, com as seguintes questões norteadoras: para você, o que significou a cirurgia cardíaca? Como você se sentiu durante a internação na UTI? Você se sentiu tocado na UTI?

Os dados coletados foram registrados após cada sessão de observação ou entrevista, em um diário de campo. As entrevistas formais foram gravadas com consentimento informado do entrevistado e, posteriormente, transcritas na íntegra.

\section{A análise dos dados}

MINAYO (1998) afirma que o processo de análise de dados relaciona as estruturas significantes com as estruturas dos significados dos enunciados. Os dados são relacionados com os fatores que os caracterizam; variáveis psicossociais, contexto natural e processo de produção da mensagem. Uma boa análise interpreta o discurso dentro de um quadro de referências onde a ação objetivada permite ultrapassar a mensagem manifesta e atingir os significados latentes (VILA, 2001).

Neste estudo, seguimos os passos preconizados por GERMAIN (1986) para a análise dos dados: codificação, categorização, interpretação dos dados e derivação dos temas. Segundo esta autora, os dados são revistos periodicamente quanto a seus conceitos emergentes, classificações ou padrões sendo, assim, passados de um nível concreto para um nível de maior abstração. 
Com a análise dos dados emergiram duas categorias principais, com suas subcategorias, que deram sentido ao significado do toque na perspectiva de pacientes no pós-operatório de cirurgia cardíaca. A primeira, Cirurgia Cardíaca, com as subcategorias: medo de morrer, permanecer na UTI e a fé em Deus. A segunda, O Toque, com as subcategorias: forma especial de tratar e reconhecimento humano.

\section{Cirurgia Cardíaca}

Esta categoria refere-se aos significados expressos pelos informantes sobre a cirurgia e o pósoperatório na UTI. As subcategorias apresentam as falas dos informantes, revelando que a cirurgia e o pós-operatório têm um significado amplo envolvendo sentimentos como o medo, sofrimento, a fadiga e o desconforto em permanecer na UTI. Os informantes relataram, também, a importância da fé em Deus como importante instrumento para superação de um momento difícil como este.

\section{- O medo de morrer}

Nesta subcategoria estão reunidos os depoimentos em que os informantes mencionam o medo de morrer durante a cirurgia cardíaca.

\section{"Fiquei com medo de morrer na cirurgia" (E10) "Meu maior medo era morrer e deixar minha filha pequena". (E2) \\ "Para mim, mexer no coração era a última coisa a fazer. Fiquei muito abatido, tive medo de não voltar mais".(E10)}

Os informantes demonstraram a fragilidade do ser humano frente a uma situação de risco. BARBATO et al (1982) afirmam que mais de um quarto dos pacientes internados com problemas cardíacos citaram a angústia, a ansiedade e o medo de morrer como os maiores problemas psicosócioespirituais. A maioria dos pacientes internados na UTI teme pela vida, julgando-a ameaçada.

É importante que a equipe multiprofissional não se esqueça que cada paciente traz consigo suas próprias fantasias acerca da experiência cirúrgica, sendo fundamental dar atenção aos aspectos emocionais de pacientes e familiares para facilitar o enfrentamento deste momento de angústia e sofrimento. Nesta perspectiva, o papel da enfermagem deve estar voltado para o cuidado afetivo e o conforto, instrumentos necessários para aliviar a dor, o medo e o sofrimento.

\section{- Permanecer na UTI: fadiga, barulho e desconforto. \\ Nesta subcategoria, os informantes mencionaram situações e sentimentos vivenciados durante sua permanência na UTI. Os informantes se referiram, principalmente, à fadiga, ao desconforto}

físico provocado pelos artefatos utilizados no pósoperatório e ao barulho no contexto da terapia intensiva.

"A gente pensa que vai morrer na UTI com aqueles aparelhos na boca. A gente fica fadigada".(E2)

"A pior coisa da UTI foi aquele tubo na garganta. Machucava, doía, eu vomitava, tinha muita secreção".(E1)

"Quando acordei na UTI, senti muito medo, fadiga com o barulho das máquinas". (E2)

"Fiquei naquele colchão quente, aqueles aparelhos, nem podia mexer com medo de sentir dor". (E3)

MACIEL (1996) afirma que, dentre os procedimentos técnicos que incomodam o paciente, a entubação traqueal tem sido destacada pelos pacientes como o mais freqüente desconforto. A sobrecarga sensorial tem uma repercussão importante durante 0 pós-operatório. O paciente poderá apresentar sintomas como: perda da percepção do tempo e espaço, tédio, ansiedade e medo, depressão e agitação (HỦDAK \& GALLO, 1997).

WALDOW (1998) afirma que a abordagem carinhosa, interessada, respeitosa, o esclarecimento e a educação do paciente constituem elementos-chave para a tranqüilidade, a segurança, a confiança, a colaboração e a aceitação do cuidado. SILVA (2000) ressalta que mesmo os pacientes em estado crítico relatam que os problemas sentidos por eles e suas expectativas em relação à equipe de enfermagem recaem mais na área expressiva do que na instrumental: queixam-se da separação da família, do ambiente desconhecido e agressivo, da quebra dos hábitos de alimentação, do desrespeito à privacidade e da falta de atenção individualizada.

Observamos que, apesar de se referirem ao medo, ao incômodo e ao cansaço por estarem na UTI, os informantes mencionaram aspectos positivos como, por exemplo, a sensação de segurança e o fato de serem bem cuidados pela equipe multiprofissional.

"Na UTI, muitas pessoas me disseram palavras de conforto".(E1)

"Fui muito bem tratada. O pessoal da UTI é legal." Lá eles te tratam com muito carinho e isto levanta mais o da gente (E2)

"Me trataram bem na UTI. Não saíam de perto de mim, perguntando o que eu estava sentindo".(E9)

BARCELLOS \& CAMPONAGRA (2001) reforçam a importância do papel do enfermeiro, esclarecendo que este papel vai muito além do cuidado técnico. Alcança um compromisso com o cuidado humano e solidário. As bases desse cuidado residem na cooperação, nas explicações que orientam 
o paciente, na educação para o cuidado, na explicação de cada procedimento técnico, nas palavras estimulantes e no toque afetivo.

Observamos que os informantes sentiram o impacto da tecnologia utilizada durante o pósoperatório da cirurgia cardíaca como uma experiência desgastante e difícil, mas, ao mesmo tempo, ressaltaram a proximidade e o carinho que receberam e que, certamente, exerceu um efeito benéfico em sua recuperação. Ninguém questiona a importância da tecnologia porque ela, em si mesma, não é benéfica nem maléfica. A UTI precisa e deve utilizar os recursos tecnológicos cada vez mais avançados, porém, os profissionais não deveriam esquecer que a máquina jamais substituirá a essência humana (SILVA, 2000).

Concordamos com CATARINO et al (!996) quando afirmam que atualmente pretende-se uma UTI que, mais do que excelência de instalações e novos equipamentos, seja resultante da interação entre o cuidado humano e excelência técnica. O exercício de todos os atos, técnicos ou não, pressupõe a compreensão do respeito pelo homem, que é alguém que sofre e tem receios, sobretudo se não sente o calor humano. O respeito transmite aos cuidados toda uma dimensão humana, constituindo a base de qualquer relacionamento.

\section{- A fé em Deus}

Nesta subcategoria, reunimos os depoimentos onde os informantes relatam que depositaram em Deus, a esperança de sucesso na cirurgia. A crença em Deus aparece como indispensável para o enfrentamento desta fase de sofrimento, angústia e insegurança. A visão religiosa neste contexto surge tanto para explicar e justificar a doença, como para buscar alternativas de solução do problema.

"Entreguei para Deus".(E5)
"Mas me peguei muito com Deus. Deus é pai e
é nosso médico".(E4)
"Estou nas mãos de Deus".(E2)
"Tudo correu do jeito que o Senhor
permitiu".(E7)
"Só o Senhor poderia resolver". (E6).

KLUBER-ROSS (1988) afirma que nos momentos de crise é imprescindível para o paciente que se preserve sua liberdade de expressão psicoespiritual por meio da religião que se torna, assim, o referencial do homem em meio aos fenômenos que o envolvem. O vínculo religioso transmite valores básicos que amenizam as reações psicológicas em situações de crise.

Dessa forma, a interpretação religiosa durante o pós-operatório de cirurgia cardíaca torna-se muitas vezes mais abrangente do que a disfunção orgânica em si. BATISTA (2001) afirma que esta circunstância, a proximidade com o sagrado na UTI exerce dupla influência sobre o paciente, porque ele se sente capaz explicar a doença e de arquitetar um prognóstico do seu estado, percebendo alternativas otimistas para conviver com a crise instalada.

\section{O Toque}

Esta categoria reúne os depoimentos que refletem o significado do toque durante sua permanência na UTI. Apesar de permanecerem temporariamente sob efeito anestésico, a maioria, logo após passado este efeito, percebeu o toque e foi capaz de descrever as atividades à sua volta. Muitos não se lembraram de quem os tocou, alguns só viram o vulto. Contudo, afirmaram ter sentido a presença de alguém ali ao seu lado, cuidando e lhes dando conforto.

SILVA (1996) afirma que os pacientes graves apresentam expressões positivas se tocados de forma afetiva e não apenas quando o toque é necessário para a realização de procedimentos técnicos.

Observamos que os pacientes reagiram bem ao toque, à atenção e ao carinho. Esse cuidado aumenta a auto-estima e reduz a ansiedade, pois se consubstancia na atenção centrada na pessoa e não somente em sua doença. Percebemos, então, que a comunicação é um processo no qual compartilhamos não só idéias, mas principalmente imagens, sentimentos e mensagens. Por isso, a maioria dos pacientes pode perceber que foi tocada de forma amorosa e afetiva.

\section{- Tocar: estar junto, demonstrar carinho e dar coragem}

Nesta subcategoria, reunimos os depoimentos em que os informantes mencionam o toque como uma demonstração de carinho, companhia e principalmente como forma de transmitir força e coragem.

“... e senti que não estava sozinha." (E1)

"O toque é ótimo. É muito importante. Pensei que ia morrer, mas quando alguém pegou em minha mão senti que não estava sozinho." (E3) "(...) uma sensação muito boa de que alguém gosta da gente, preocupa com a gente." (E6) "Tocar é importante porque a pessoa está tendo um carinho com você." (E9)

"Acho que o toque é muito importante. Faz bem, estimula a gente. Dá vontade de sair daquela situação." (E6)

"Eu senti que não estava só, sentia aquela força..." (E9)

"Eu acho que é uma forma muito especial de carinho de um ser humano para outro que está passando por dificuldades." (E10)

"O toque é um reconhecimento humano. Com ele, senti melhora." (E11) 
A perspectiva dos informantes confirma 0 pensamento de BOFF (1999) ao referir-se à carícia, que para o autor representa o modo de ser cuidado, pois é uma mão revestida de paciência tocando sem agredir, permitindo a mobilidade do ser com quem entramos em contato. Assim, a mão de quem toca torna-se algo além do que uma simples mão, pois no estabelecimento de relações transmite quietude, carinho tocando assim o eu profundo e não apenas a superfície da consciência".

A última fala citada acima traduz o reconhecimento da existência do outro, do estar presente, da importância do outro. Nesta perspectiva, o toque afetivo significa a valorização do ser humano como nosso próximo. FIGUEIREDO et al (1996) também afirmam que "tocar é o significado humano, é dar vida àquele que é tocado". Observamos que muitos profissionais, principalmente, de enfermagem, utilizam o toque afetivo, isto é, o toque espontâneo que não integra, necessariamente, os procedimentos de enfermagem, mas envolve sentimentos de empatia, apoio, amizade e proximidade com o paciente, mas de forma automática, sem perceber os efeitos provocados, como a sensação de bem-estar que aumenta a confiança e reduz a ansiedade do paciente.

\section{- Tocar: conforto, confiança, tranqüilidade, segurança e paz interior}

Nesta subcategoria, os informantes atribuem ao toque o poder de proporcionar conforto e tranqüilidade naquela situação de sofrimento físico e emocional. O toque aparece ainda com o significado de instrumento que transmite segurança e paz interior.

"Senti conforto, paz interior, tranqüilidade (...)"
(E5)
"Quando as pessoas me tocavam eu sentia
confiança..." (E)
"Eu me senti mais segura." (E2)
"Eu acho que o toque é muito importante
porque transmite calma." (E5)
"Quando pegaram na minha mão eu senti que
tudo ia dar certo" (E7)
"A gente fica muito aflita, passando mal com
aquelas coisas (aparelhos). Então, quando
alguém pega na mão e conversa, a gente fica
mais calma, acaba o medo. Contribui muito
para a melhora." (E5)

MENDES et al (1991) afirmam que, pelo ato de cuidar, o enfermeiro está expressando uma atitude de preocupação com o paciente, o que é muito importante para seu bem estar. $O$ toque afetivo além de contribuir para reduzir o medo e ansiedade, proporciona bemestar físico e emocional aos pacientes. (FIGUEIREDO et al, 1996; SILVA \& BELASCO JÚNIOR, 1986).

Durante a realização de uma das entrevistas, a mãe da paciente esteve junto e consideramos importante relatar seu discurso uma vez que o sentimento demonstrado sobre a importância do cuidado e do toque reflete o que está sendo discutido nesta pesquisa:

\begin{abstract}
"Ela quase não viu nada na UTI mas, eu vi que o trabalho de vocês é muito bonito. O corpo de enfermagem é muito bonito e carinhoso. Isso é humano demais no mundo que estamos vivendo hoje, tão sem amor, sem carinho pelas pessoas, principalmente quando elas estão fragilizadas. Eu vi a cara de delicadeza, de carinho das enfermeiras com os pacientes. Eu fiquei de braços cruzados e a enfermeira me disse que podia pegar na mão dela.. Eu tirei a mão de debaixo dos braços e toquei a cabeça dela, carinhei ela. Então a enfermeira teve aquele carinho de me falar para tocar na paciente para ela se sentir feliz, que estava sendo acompanhada, olhada. O carinho é muito grande, a UTI é muito humana..." (E6).
\end{abstract}

HUDAK \& GALLO (1997) afirmam que a família é uma extensão do paciente e que o cuidado se estende de um para a outra. Os familiares de um paciente sofrem tanto quanto ele. Sentem medo, ansiedade e desamparo por não poder interferir no tratamento e ajudar seu parente naquele momento. $\mathrm{O}$ ambiente hospitalar constitui para essas famílias um local amedrontador, cujas rotinas e exigências servem para separá-las de seus entes queridos.

Nesta perspectiva, a enfermagem deve ajudar a família, dar-lhe atenção, ouvindo-lhe as queixas e, ainda, fornecer informações precisas, favorecendo o contato com a realidade. Quando bem orientados, os familiares incentivam $o$ doente $e$ auxiliam na recuperação. A troca de informações entre o enfermeiro e a família tem função humanística e social, além de proporcionar ao familiar, segurança e confiança no atendimento (BEZERRA, et al, 1998).

\section{CONSIDERAÇÕES FINAIS}

Esta pesquisa permitiu compreender que a cirurgia cardíaca traz consigo uma série de sentimentos e expectativas como o medo de morrer, a difícil necessidade de permanecer na UTI e a fé em Deus como instrumento para superar este momento de estresse e sofrimento físico e emocional.

Evidencia-se nesta pesquisa o quanto questões referentes ao ambiente tecnológico da terapia intensiva agridem diretamente o paciente que, neste contexto, referem-se ao barulho e ao desconforto físico e emocional gerados pelos artefatos inerentes ao pósoperatório de cirurgia cardíaca.

Observamos que o paciente no pós-operatório de cirurgia cardíaca tem a estima e a auto-imagem abaladas, necessitando, por isso, de palavras, gestos, apoio e incentivo por parte da equipe de enfermagem, 
ao lado de cuidados técnicos necessários à sua reabilitação.

Para os informantes, o toque tem um significado que envolve essencialmente o aspecto afetivo, como a segurança, o conforto, a tranqüilidade, a compreensão, o olhar com interesse, o encorajamento, enfim, uma forma terapêutica que capacita o profissional a cuidar do paciente e familiares, de forma consciente e humana.

Acreditamos que o toque afetivo aliado ao instrumental será capaz de viabilizar a melhoria do cuidado, principalmente na UTI, ambiente permeado por sofrimento físico e emocional para quem cuida e quem é cuidado. Assim, estaremos qualificando o atendimento e de fato contribuindo para a humanização do atendimento em UTI.

Este trabalho não pretende esgotar o tema acerca da compreensão do toque na perspectiva de pacientes no pós-operatório de cirurgia cardíaca. No entanto, pretende estimular a realização de novos estudos e motivar profissionais que atuam na terapia intensiva, em especial, a equipe de enfermagem, a adotarem o toque como instrumento para cuidar de pacientes e familiares, resgatando o real sentido do cuidar, por meio do amor e da empatia.

\section{REFERÊNCIAS BIBLIOGRÁFICAS}

BARCELOS, V. R. de CAMPONAGRA, S. O uso da comunicação não-verbal no cuidado ao paciente cardiopata: percepções da equipe de enfermagem. In: COSTENARO, R. G. S. Cuidando em enfermagem: pesquisas e reflexões. Santa Maria (RS): UNIFRA; 2001.

BARBATO, M. G. et. al.. Problemas psicossócio espirituais dos coronarianos internados em unidades coronarianas. Rev. Bras. Enfermagem. v. 35, p.7-16, 1982.

BATISTA, M. de A. Presença do sagrado em um momento crítico: internação em uma Unidade de Terapia Intensiva. Goiânia, 2001. 100p. Dissertação (Mestrado). Universidade Católica de Goiás.

BEZERRA, A. L. Q.; DALBEN, L. W.; CAMARGO, M. N. V.; PINHEIRO, V. F.o. Gestos e posturas do enfermeiro durante a orientação a familiares de pacientes internados em unidades de terapia intensiva. Rev. Esc. Enfermagem, USP. v. 32, n. 2, p. 134-139, 1998.

BOFF, L. Saber cuidar. 2. ed. São Paulo, Vozes, 1999. CATARINO, J.; CASSIANO, J.; SILVA, R. C. O respeito como princípio moral e básico e principal em enfermagem. Nursing Portuguesa, n. 99, p. 21-4, abril 1996.

FIGUEIREDO, N. M. A.; MACHADO, W. C. A.; PORTO, I. S. O toque e a prevenção de escaras. Rev. Enf. UERJ, edição extra, p. 71-80, 1996.

GERMAIN, C. Ethnography the mehtod. In: MUNHAKK, P. L.; OILER, C. J. Nursing research: a qualitative perspective. Norwalk: appliton-century-crofs, 1986. Cap. 8, p. 147-62.

HUDAK, C. M.; GALLO, B. M. Cuidados intensivos de enfermagem: uma abordagem holística. 6. ed. Rio de Janeiro, Guanabara Koogan, 1997.

KLUBER-ROSS, E. Sobre a morte e o morrer. São Paulo: Martins Fontes, 1998.

MACIEL, I. C. F. Sentimentos e expectativas do paciente acerca do tratamento na unidade de terapia intensiva. Fortaleza, 1996. 77P. Monografia. Universidade Estadual do Ceará.

MENDES, I. A. C., TREVIZAN, M. A., HAYASHIDA, M. \& SONOBE, H. M. Comunicação com o Paciente: o teórico e o concreto na enfermagem de âmbito hospitalar. Rev. Bras. Enf., v. 44, n. 2/3, p. 98-102, 1991.

MINAYO, M. C. de S. O desafio do conhecimento: pesquisa qualitativa em saúde. 5. ed. São Paulo - Rio de Janeiro, HUCITEC-ABRASCO, 1998.

SILVA, M. J. P da. Comunicação tem remédio: a comunicação nas relações interpessoais sem saúde. 2. ed. São Paulo, Gente, 1996.

SILVA, M. J. P da. Humanização em unidade de terapia intensiva. In: CINTRA, E. A.; NISHIDE, V. M.; NUNES, W. A. Assistência de enfermagem ao paciente crítico. São Paulo, Atheneu, 2000. Cap. 1, p. 1-11.

SILVA, M. J. P da; BELASCO JÚNIOR, D. Ensinando o toque terapêutico: relato de uma experiência. Rev. Latino-Am. de Enf., v. 4, n. especial, p. 91-100, 1986.

VILA, V. S. C. O significado cultural do cuidado humanizado em unidade de terapia intensiva: muito falado e pouco vivido. Ribeirão Preto, 2001. 115p. Dissertação (Mestrado) - Escola de Enfermagem de Ribeirão Preto - Universidade de São Paulo.

WALDOW, V. R. Cuidado humano: o resgate necessário. Porto Alegre: Sagra Luzzato, 1998.

Texto Recebido em 25/11/2005.

Publicação aprovada em: 29/12/2005 